Abstracta Iranica Abstracta Iranica

Revue bibliographique pour le domaine irano-aryen

Volume 40-41 | 2019

Comptes rendus des publications de 2017-2018

\title{
Pierfrancesco Callieri, Adriano Valerio Rossi (eds.). Civiltà dell'Iran: passato, presente, futuro. Atti del Convegno Internazionale Roma, 22-23 febbraio 2013
}

\section{Rémy Boucharlat}

\author{
(2) OpenEdition \\ Journals \\ Édition électronique \\ URL : http://journals.openedition.org/abstractairanica/51067 \\ DOI : 10.4000/abstractairanica. 51067 \\ ISBN : 1961-960X \\ ISSN : 1961-960X \\ Éditeur : \\ CNRS (UMR 7528 Mondes iraniens et indiens), Éditions de l'IFRI
}

\section{Référence électronique}

Rémy Boucharlat, « Pierfrancesco Callieri, Adriano Valerio Rossi (eds.). Civiltà dell'Iran: passato,

presente, futuro. Atti del Convegno Internazionale Roma, 22-23 febbraio $2013 »$, Abstracta Iranica [En ligne], Volume 40-41 | 2019, document 6, mis en ligne le 30 décembre 2019, consulté le 19 avril 2021. URL :

http://journals.openedition.org/abstractairanica/51067; DOI : https://doi.org/10.4000/ abstractairanica.51067

Ce document a été généré automatiquement le 19 avril 2021.

Tous droits réservés 


\title{
Pierfrancesco Callieri,
} Adriano Valerio Rossi (eds.). Civiltà dell'Iran: passato, presente, futuro. Atti del Convegno Internazionale Roma, 22-23 febbraio 2013

\author{
Rémy Boucharlat
}

\section{RÉFÉRENCE}

Pierfrancesco Callieri, Adriano Valerio Rossi (eds.). Civiltà dell'Iran: passato, presente, futuro. Atti del Convegno Internazionale Roma, 22-23 febbraio 2013. (Il novissimo Ramusio 6). Roma: Scienze e lettere, 2018, 325 p., 40 pl. Couleurs.

1 Ce colloque était organisé avec le concours du service culturel iranien à Rome, par plusieurs organismes scientifiques l'ISMEO, l'association qui a fait suite à la disparition de l'IsMEO, grande institution nationale italienne, le Museo Nazionale d'Arte Orientale de Rome, les universités, la Sapienza à Rome, l'Orientale à Naples et Alma Mater à Bologne. En réunissant différentes contributions, il visait à rendre visible la diversité des études sur l'Iran en Italie, qu'il s'agisse d'art et d'archéologie, histoire, littérature et jusqu'au cinéma, complétée par la présentation des collections iraniennes du Musée national d'art oriental à Rome.

2 La liste des contributions rend compte de cette diversité. Dans le domaine de l'archéologie, ce sont seulement les articles sur les époques historiques préislamiques qui font l'objet d'un abstract séparé.

\section{L'uomo e l'ambiente}

- Lorenzo Costantini, Matteo Delle Donne: “Agricoltura e ambiente dell'Iran orientale durante la protostoria" 
- Massimo Vidale: "Irrigation and Canals in Ancient Iran. Resurrecting Wittfogel? (voir le cr par R. Boucharlat dans AI40-41, rubrique 3.0, $\mathrm{n}^{\circ} 18$ )

- Raffaele Biscione: “L'Iran nord-occidentale nell'altopiano armeno: la complessità sociale fra il Bronzo Antico ed il periodo urarteo"

- Seyyed Mansur Seyyed Sajjadi: "Funzioni delle catacombe nella necropoli di Shahr-i Sokhta, Sistan"

\section{Le forme del costruire}

- Pierfrancesco Callieri: “Terra e pietra nell'architettura dell'Iran degli imperi preislamici” (voir le cr par S. Gondet dans AI40-41, rubrique 3.0., n 6)

- Antonio Invernizzi: "L'Iran arsacide tra Achemenidi e Sasanidi" (voir le cr par L. Gregoratti dans AI40-41, rubrique 3.2.3., $\mathrm{n}^{\circ}$ 38)

- Barbara Kaim: "Architecture of Zoroastrian Fire Temples" (voir le cr de M. Minardi dans AI40-41, rubrique 3.2.3., $\mathrm{n}^{\circ}$ 5)

-Vito Messina: “I rilievi rupestri d'Elimaide” (voir le $\mathrm{cr}$ de L. Gregoratti dans AI40-41, rubrique 3.2.3., $\mathrm{n}^{\circ}$ 39)

- Giovanni Curatola: "Decorazione architettonica nell'Iran di epoca islamica"

- Lorenz Korn: "Between Architectural Design and Religious Politics: Aspects of Iranian Mosque Architecture of the Saljuq Period"

• Eskendar Mokhtari Taleghani: "The Contemporary Architecture of Iran"

\section{Imagginario e scittura}

- Gianroberto Scarcia: "Iran e Turan nella cultura persiana. Status quaestionis, anzi quaestionum"

- Alberto Ventura: "Sufismo e letteratura in Iran"

- Mario Casari: "Idee dei giardini del mondo: privilegiati scambi letterari tra Italia e Iran"

- Bianca Maria Filippini: “Alcune considerazioni sui rapporti tra cinema e letteratura nell'Iran d'epoca pahlavi"

-Angelo Michele Piemontese: "Contatti culturali d'Italia e Iran in epoca medievale e moderna"

\section{Le collezioni iraniche del Museo Nazionale d'Arte Orientale 'Giuseppe Tucci', Roma}

- Giovanna Lombardo: “L'Iran protostorico nelle collezioni del Museo Nazionale d'Arte Orientale "Giuseppe Tucci"

- Paola D’Amore: “Le collezioni iraniche del Periodo del Ferro del Museo Nazionale d'Arte Orientale "Giuseppe Tucci"

- Paola Piacentini: "Dagli Achemenidi ai Sasanidi. Arte imperiale nelle collezioni del Museo Nazionale d'Arte Orientale "Giuseppe Tucci" (voir le cr par M. Minardi dans AI40-41, rubrique 3.2.3., $\mathrm{n}^{\circ}$ 6)

- Michael Jung: “Le collezioni e le attività del settore islamico dell'Iran del Museo Nazionale d'Arte Orientale" 


\section{AUTEURS}

RÉMY BOUCHARLAT

UMR 5133 CNRS-Université de Lyon 